\title{
Rapid synthesis of di-1,2,4-oxadiazoles pyridyl compounds
}

\author{
Anderson B. da Silva and Juliana A. Vale* \\ Laboratório de síntese e biocatálise da Paraíba, Departamento de Química, Universidade Federal da \\ Paraíba, João Pessoa-PB, 58059-970 \\ *juliana@quimica.ufpb.br
}

Keywords: di-1,2,4-oxadiazoles pyridyl, microwave, 2,6-di-amidoxime pyridyl

\section{INTRODUCTION}

The 1,2,4-oxadiazoles derivatives are compounds that exert a variety of important biological activity, such as anti-inflammatory, antiviral, and cardiovascular activities ${ }^{1}$. These compounds have also been applied as ligands on metal complexes ${ }^{2}$ and liquid crystal materials. ${ }^{3}$

In this work, we have investigated the rapid synthesis of some new di-1,2,4-oxadiazoles pyridyl compounds by two different methods between as shower the scheme 1.<smiles>C=Cc1nc(C2CCCC(c3noc(P)n3)N2)no1</smiles><smiles>C=C=NOC(=O)OC(=O)C#N</smiles>

Scheme 1. Retrosynthesis of di-1,2,4-oxadiazoles pyridyl compounds

\section{RESULTS AND DISCUSSION}

Initially, 2,6-diamidoxime pyridyl (2) was synthesized in quantitative yield from commercially available 2,6dicianopyridine (1) and hydroxylamine hydrochloride in $\mathrm{H}_{2} \mathrm{O}$ (Scheme 2).<smiles>N#Cc1cccc(C#N)n1</smiles>

1

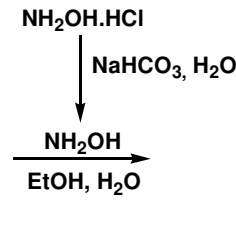<smiles>N/C(=N\O)c1cccc(/C(N)=N/O)n1</smiles>

2
Scheme 2. Synthesis of 2,6-diamidoxime pyriyl

Two methods for preparing 1,2,4-dioxadiazoles pyridyl compounds via reaction between 2,6diamidoxime pyridyl and an anhydride were compared, namely the standard thermal method (Method A) and that by microwave irradiation (Method B). The results are shown in Table 1.
Table 1. Yield comparison for the syntheses of di-1,2,4oxadiazoles pyridyl by the methods $A$ and $B$.

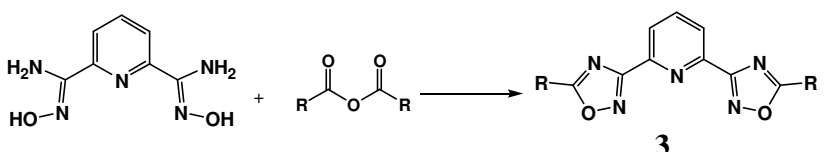

\begin{tabular}{|c|c|c|c|c|c|}
\hline \multirow[b]{2}{*}{$\begin{array}{c}\text { Compo } \\
\text { unds }\end{array}$} & \multirow[b]{2}{*}{$\mathbf{R}$} & \multicolumn{2}{|c|}{ Method A } & \multicolumn{2}{|c|}{ Method B } \\
\hline & & $\begin{array}{l}\text { Time } \\
\text { (min) }\end{array}$ & $\begin{array}{c}\text { Yield } \\
(\%)\end{array}$ & $\begin{array}{l}\text { Time } \\
\text { (min) }\end{array}$ & $\begin{array}{c}\text { Yield } \\
\text { (\%) }\end{array}$ \\
\hline $3 a$ & Methyl & 120 & 94 & 10 & $>99$ \\
\hline $3 b$ & $\begin{array}{l}\text { trifluorom } \\
\text { ethyl }\end{array}$ & 90 & 96 & 10 & $>99$ \\
\hline $3 c$ & n-propyl & 150 & 90 & 10 & $>99$ \\
\hline $3 d$ & n-hexyl & 150 & 90 & 10 & 94 \\
\hline $3 e$ & Phenyl & 240 & 0 & 60 & 0 \\
\hline
\end{tabular}

Conditions: The anhydrides were used as solvent. Yield refers to isolated yields. The purification was done by recrystalization from ethyl acetate. The products were characterized by ${ }^{1} \mathrm{H}$ and ${ }^{13} \mathrm{C}$ NMR, GC-MS and ESI-TOFMS. Experiments with microwave were carried out in a Discover reactor.

The compounds synthesized from alkyl anhydrides were rapidly obtained in excellent yields (3a-3d) by using a microwave reactor. The product $3 \mathbf{e}$ was not obtained by either the two methods tested.

\section{CONCLUSION}

We obtained several new 1,2,4-dioxadiazoles pyridyl compounds in good yields and short reaction time by a method using microwave irradiation. Biological activity of these compounds are under investigation in our laboratory.

\section{ACKNOWLEDGEMENTS}

CNPq, CAPES, UFPB.

\section{REFERENCES}

${ }^{1}$ Ahn, J.-M.; Boyle, N. A.; MacDonald, M. T.; Janda, K. D. Mini Rev. Med. Chem. 2002, 2, 463.

${ }^{2}$ Steel, P. J.; Richardson, C. Inorg. Chem. Comm. 2007, 10, 884.

${ }^{3}$ Gallardo H., Cristiano R., Vieira A.A., Neves Filho R.A.W., Srivastava R.M. Synthesis 2008, 605. 